\title{
Impacto das Ações Governamentais na Arrecadação do Município de São Paulo
}

\author{
Impact of Governmental Actions on São Paulo city Collection
}

\begin{abstract}
Resumo
0 objetivo deste estudo é apresentar métodos quantitativos estatísticos para testar hipóteses referentes ao impacto das ações governamentais na arrecadação dos principais tributos de competência do município. Desde a vigência da Lei Complementar n. 116/2003, a qual ampliou a base de serviços que poderiam sofrer incidência do Imposto Sobre Serviços (ISS) para aumentar a arrecadação sem aumento de alíquotas, novas hipóteses de incidência ou criação de novos tributos. Este artigo procura isolar os efeitos relacionados às ações governamentais dos resultados de outros fatores, tais como crescimento econômico e inflação. Uma vez isolado 0 efeito da ação específica, cria-se um modelo estatístico para comparar a evolução da receita do tributo analisado em dois momentos, antes e após a vigência da ação. Modelos estatísticos econométricos de isolamento de tendência nas séries temporais por meio da regressão múltipla e uso de variáveis dummy (qualitativas) fazem parte das ferramentas utilizadas no estudo. A validação dos efeitos foi feita por meio de testes de significância estatística próprios. Como resultado, é possível concluir que houve efeito significativo da ação governamental na arrecadação dos tributos analisados.
\end{abstract}

Palavras-chave: Gestão pública; Modelo econométrico; Arrecadação; Ações governamentais.

Mauro Maia Laruccia - mauro.laruccia@gmail.com

Doutor em Comunicação e Semiótica, Mestre e Bacharel em Administração pela PUC/SP. Professor da FEA/PUCSP e analista de C\&T da Fundacentro.

Mamerto Granja Garcia - mamertog@gmail.com

Doutorando em Ciências Sociais pela PUC(SP). Professor da Faculdade de Economia e Administração da Pontifícia Universidade Católica de São Paulo.

Elisabete Adami Pereira dos Santos - betadami@pucsp.br

Mestre em Administração pela PUC(SP). Professor da Faculdade de Economia e Administração da Pontifícia Universidade Católica de São Paulo.

Arnaldo José França Mazzei Nogueira Correio - ajnogueira@pucsp.br

Doutor em Ciências Sociais pela Universidade Estadual de Campinas. Professor da Faculdade de Economia e Administração da Pontifícia Universidade Católica de São Paulo.

Artigo submetido no dia 13.06.2012 e aprovado em 18.11.2013

\section{Abstract}

The aim of this paper is to present quantitative statistical methods for testing hypotheses regarding the impacts of governmental actions on the collection of taxes imposed by the main city; under Complementary Law 116/2003, which broadened the scope of services that could suffer impact from $1 S$ S to increase revenues without increasing tax rates. This study seeks to isolate government action effects from other factors' effects such as economic growth and inflation. Once isolated the effects of each specific action, a statistical model is created to compare the tax revenue evolution assessed on two occasions, before and after the action effective date. Statistical models for isolating econometric trends in time series through the use of multiple regression and variable "dummy" (qualitative) method are part of the tools used in the study. Validation of the effects was done by means of statistical significance tests. As a result, we conclude that there are significant effects of government action on the collection of taxes assessed.

Keywords: Public Management; Econometric Model; Collection; Government Actions. 


\section{Introdução}

O objetivo deste artigo é apresentar métodos quantitativos estatísticos para testar hipóteses referentes ao impacto das ações governamentais na arrecadação dos principais tributos municipais, bem como isolar os efeitos relacionados a elas dos resultados de outros fatores, como crescimento econômico e inflação.

Os municípios brasileiros assumiram políticas simultâneas a cargo da União e dos Estados para assegurar o bem-estar social às suas populações (função de Welfare) e a promoção do desenvolvimento econômico com base nas ações de âmbito local, envolvendo o relacionamento com o setor privado, ou seja, a função desenvolvimentista (ABRUCIO; COUTO, 1996).

(...) ganha força a ideia de um Estado mais enxuto e eficiente - cada vez mais próximo do modelo liberal do "Estado mínimo" -, as políticas que ainda são tidas como de responsabilidade governamental são justamente aquelas mais compatíveis às esferas subnacionais de governo, especialmente no âmbito municipal: as áreas de saúde, educação, saneamento, habitação, transporte público etc. (...) Para assumir de forma mais abrangente as funções de welfare, os municípios precisam modificar sua estrutura administrativa e recapacitar-se financeiramente (ABRUCIO; COUTO, 1996).

Conforme Abrucio e Couto (1996) revelaram, o volume de recursos arrecadados de tributos municipais próprios aumentou consideravelmente. O Imposto Sobre Serviços (ISS), a principal fonte arrecadadora de recursos próprios, em 1991, representava um terço da receita municipal em nível nacional, $20 \%$ a mais do que o segundo mais importante imposto municipal, o Imposto Predial e Territorial Urbano (IPTU). O ISS, que incide sobre a prestação de serviços, tende a encontrar uma maior base tributária nas localidades economicamente mais dinâmicas como São Paulo (ABRUCIO; COUTO, 1996).

Segundo dados do Tesouro Nacional, em 2010, 47,3\% da receita corrente do Município de São Paulo teve sua origem na arrecadação tributária relacionada aos tributos próprios, ${ }^{1}$ dos quais $25,5 \%$ correspondem à participação do Imposto sobre Serviços de Qualquer Natureza (ISSQN) na receita corrente. A Constituição de 1988, no artigo 156, delineou as competências tributárias dos municípios e sua vigência até os dias de hoje.

Atualmente, no município de São Paulo, três tributos - Imposto sobre a Propriedade Territorial e Urbana (IPTU), Imposto Sobre Serviços de Qualquer Natureza (ISSQN) e Imposto sobre a Transmissão de Bens Imóveis "Inter Vivos" (ITBI-IV) - contribuem com aproximadamente $92 \%$ do total da arrecadação tributária de competência do município, ou seja, excluindo-se os tributos das transferências correntes, como os repasses do Imposto sobre a Circulação de Mercadorias e Serviços (ICMS) e do Imposto sobre a Propriedade de Veículos Automotores (IPVA) feitos pelo Estado de São Paulo² (fontes do Tesouro Nacional).

Desses três tributos, dois se destacaram no crescimento da arrecadação tributária do Município de São Paulo: ITBI-IV e ISSQN. De 10 de janeiro de 2005 a 31 de dezembro de 2010, a arrecadação do ITBI-IV cresceu impressionantes $267 \%$ em termos nominais e $175 \%$ em termos reais, usando-se como índice de inflação o IPCA do período com variação de $33 \%$. Nesse mesmo período, o 
ISSQN cresceu $172 \%$ nominais e $104 \%$ reais. O IPTU foi mais modesto, crescendo $90 \%$ nominais e $43 \%$ reais, entretanto, o IPTU apresentou características peculiares e uma análise dos efeitos das ações governamentais na sua arrecadação exigiria um estudo completo à parte em razão da complexidade das variáveis envolvidas. Foram muitas as ações voltadas para o IPTU objetivando a redução da inadimplência, como as leis de incentivos fiscais e o zoneamento em busca de fomentar o desenvolvimento de regiões específicas da cidade e a ampliação da zona urbana. A análise da influência das ações governamentais na arrecadação do IPTU será tema de um estudo futuro.

O crescimento acentuado na arrecadação tributária nesse período se deve a uma série de fatores econômicos e de gestão. Serão analisados os fatores relacionados à gestão tributária no Município de São Paulo a partir de 2005 e a avaliação de seu impacto na arrecadação tributária do município por meio de métodos quantitativos com modelagem estatística, a qual contribuirá para isolar os efeitos econômicos dos de gestão, além de quantificar os efeitos em termos absolutos de arrecadação.

Antes da vigência da Lei Complementar $n$. 116, de 31 de julho de 2003, a qual introduziu mudanças na lista de serviços que implicam o fato gerador do ISSQN, a arrecadação tributária própria correspondia a $46,5 \%$ da receita corrente (dados de 2002), dos quais $20,5 \%$ referentes à participação do ISSQN na receita corrente, ou seja, $5 \%$ menos do que em 2010.

A seguir, o gráfico da Figura 1 mostra a evolução da participação da receita dos principais tributos próprios na receita corrente para o período de 2002 a 2010 (BRASIL, 2012). Importante fazer essa análise, uma vez que a receita corrente é destinada ao custeio do município, como pagamento de pessoal, manutenção de escolas, hospitais e postos de saúde, continuidade dos serviços prestados ao munícipe, pagamento de precatórios, da parte da dívida fundada e do Programa de Formação do Patrimônio do Servidor Público (Pasep) e, em alguns casos, investimento, cobrindo valores que deveriam ser liquidados pelas receitas de capital.

Atualmente, por lei, $31 \%$ das receitas com impostos, pertencentes à receita corrente, são destinados ao custeio da educação e $15 \%$ ao da saúde. Além disso, quase 3\% da receita corrente líquida é dirigida ao pagamento de precatórios. 
Figura 1: Evolução da participação dos principais tributos próprios na receita corrente.

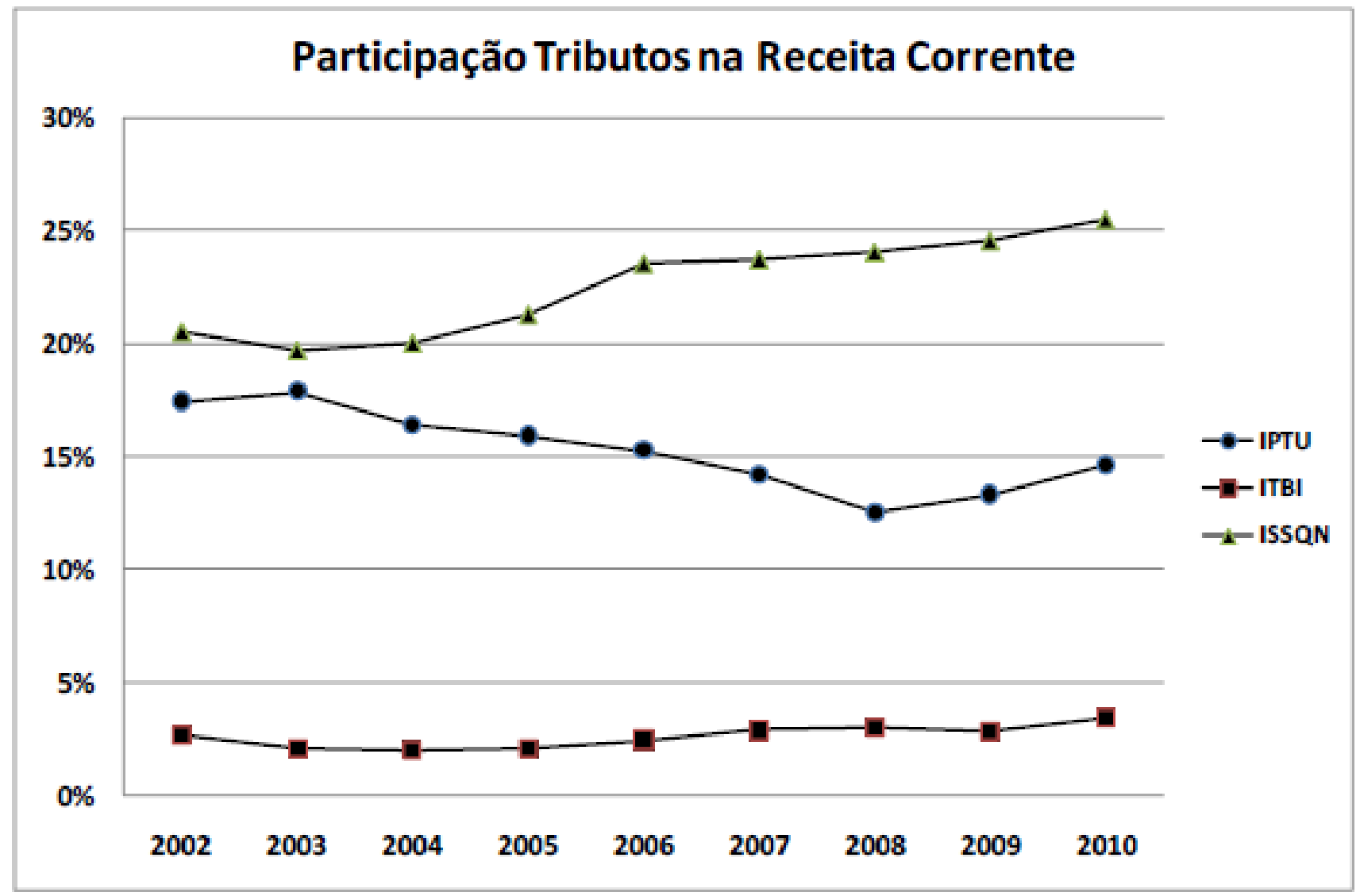

Fonte: Brasil, 2012.

Há, portanto, fortes evidências de que a explicação para esse crescimento não está apenas no efeito econômico, pois a evolução do Produto Interno Bruto (PIB) no período ficou muito aquém do aumento real da arrecadação tributária própria. Pode-se demonstrar, e esse é o objetivo deste estudo, que esse salto se deve, principalmente, às ações governamentais adotadas em concomitância à ocorrência dos efeitos da Lei Complementar n. 116, no caso do ISSQN, a partir de 2005, no que tange aos tributos próprios, a respeito dos quais haverá um breve histórico.

\section{Discussão teórica}

\subsection{Imposto sobre a propriedade predial e}

territorial urbana (IPTU)

O imposto sobre a propriedade predial e territorial urbana, conhecido pela sigla IPTU, corresponde ao tributo de maior identificação com sua competência municipal. A constituição de 1891, em seu artigo 9o, item 20, determinava que fosse de competência exclusiva dos Estados decretar impostos sobre imóveis rurais e urbanos. Foi tão somente na constituição de 1934 que o IPTU passou efetivamente a ser tributo de competência municipal, distinguindo-se a incidência predial e territorial. Essa distinção foi ampliada na constituição de 1937, em que se atribuiu aos Estados a competência privativa de decretar imposto sobre a propriedade territorial, exceto a urbana, que seguiria sendo de competência municipal (art. 24, inc. II). 
Na Constituição de 1967, o IPTU passou a ser inteiramente de competência do município, exceto os imóveis considerados rurais, cuja tributação é de competência da União, designada como Imposto sobre a Propriedade Territorial Rural (ITR). O entendimento do que é zona urbana, ou seja, incidência do IPTU nos imóveis nela inseridos, está descrito no Código Tributário Nacional (CTN), lei ordinária federal n. 5.172, de 25 de Outubro de 1966, recepcionada pela constituição de 1988 e assumindo status de lei complementar.

\subsection{Imposto sobre a transmissão de bens móveis Inter Vivos (ITBI-IV)}

Tributo que tem gerado muitas controvérsias quanto à competência de sua aplicação, o imposto sobre a transmissão de bens imóveis Inter vivos (ITBI-IV) origina-se na formação do Estado português, quando se cobrava Serviço de Impostos de Sua Alteza (Sisa), tributo que incidia na transmissão de bens móveis, semoventes e imóveis. Faoro (2001) destaca a importância e a abrangência desse tributo no sistema tributário do recém-formado Estado português:

No fim do séculoXIV a Sisa, devida ao tesouro pelos consumidores na compra e venda e na troca de mercadorias, ocupa o primeiro lugar no orçamento, recaindo sobre toda a gente, nobres, eclesiásticos e plebeus, com o rompimento do privilégio da imunidade. (...) a sisa, agora o principal imposto, quebrou as imunidades aristocráticas, penetrando em todas as transações de compra, venda $e$ troca (FAORO, 2001, p. 21-56).

No Brasil, esse tributo tem sua origem atrelada à vinda da família real em 1808, sendo instituído em junho de 1809, por meio do Alvará n. 3 , inciso I. Na ocasião, recebeu a denominação de imposto da Siza. ${ }^{3} \mathrm{~A}$ alíquota correspondia a $10 \%$, conforme texto original do item I do alvará.

$\mathrm{Na}$ constituição de 1891, o imposto passou a ser competência tributária dos Estados, designado simplesmente como imposto devido na ocorrência de transmissão de propriedade. A constituição de 1934 dividiu o imposto em dois fatos geradores: transmissão de propriedade Causa Mortis (hereditária) e transmissão de propriedades resultante das transações "Inter Vivos." De qualquer forma, o imposto seguia sendo de competência tributária dos Estados. A constituição de 1946 ampliou a incidência do imposto incluindo como fato gerador a incorporação de propriedade imobiliária ao capital social das empresas, situação conhecida como conferência de bem imóvel ao capital social.

Ojogo de disputa entre Estados e Municípios culmina com a Emenda Constitucional $\mathrm{n}$. 5 , de 21 de novembro de 1961, que deu nova redação ao sistema tributário nacional da Constituição de 1946, deixando para a competência tributária municipal o imposto sobre a transmissão de bens móveis Inter Vivos e sua incorporação ao capital de sociedades. Permanece na competência tributária dos Estados a transmissão Causa Mortis.

Dandosequênciaà disputapelacompetência tributária do imposto de transmissão de propriedade Inter Vivos, os Estados conseguem propor e aprovar a Emenda Constitucional n. 18, de 1965, resgatando a competência tributária do ITBI-IV. Somente com a constituição de 1988 , esse tributo volta a ser de competência municipal.

A grande polêmica envolvendo o ITBI-IV se 
deve às características peculiares de cada transação em que ocorre a transmissão da propriedade do imóvel. O ITBI municipal definequeaprevisãodesuaincidênciaobriga que seja por ato oneroso. Assim, doações Inter Vivos e transmissão hereditária, por exemplo, são fatos geradores do ITBI estadual, o qual é designado por Imposto de Transmissão Causa Mortis e Doação (ITCMD), pois se trata de atos gratuitos. $\mathrm{Na}$ transmissão hereditária de bens imóveis, caso haja excesso de quinhão ${ }^{4}$ de algum sucessor, cabe o ITBI municipal sobre o valor excedente, pois compreende-se que $o$ herdeiro que recebeu excesso de quinhão transacionou com o que recebeu menos, subentendo-se haver ato oneroso, a menos que haja prova cabal que se trata de doação de um herdeiro ao outro. $O$ grande problema ocorre quando herdeiros abrem mão, a título gratuito, de parte ou de todo quinhão em benefício de outro da linha sucessória sem comprovação de ato de doação. Como a transmissão envolve bens móveis e imóveis, sempre resta dúvida se realmente ela ocorreu de forma gratuita ou se houve negociação com bens móveis do montante partilhado.

\subsection{Imposto Sobre Serviços de Qualquer Natureza (ISSQN)}

O ISSQN tem sua origem na Emenda Constitucional n. 18, de 10 de dezembro de 1965, artigo 15, deixando a cargo de lei completar a lista de serviços que constituem fato gerador do imposto. Somente com o Decreto Lei n. 406, de 1968, a lista de serviços que constituem fatos geradores do ISSQN passou a vigorar.A lei Complementar n. 116, de 31 de julho de 2003, amplia essa lista, incluindo, por exemplo, os serviços relacionados à atividade bancária.
Ainda falta muito para que o conceito do que é serviço, fato gerador do ISSQN, seja pacificado no ordenamento jurídico brasileiro. Essa questão pode ser facilmente constatada pela grande quantidade de processos judiciais contestando a incidência do ISSQN nas mais variadas atividades econômicas. É possível citar como exemplo os serviços relacionados no item 3 da lista de serviços da Lei Complementar n. 116: serviços prestados mediante locação, cessão de direitos de uso e congêneres. Esses serviços geram controvérsia quanto ao conceito de serviço, pois muitos juristas o definem como obrigação de fazer, ou seja, fornecimento de energia braçal ou mecânica, de intelecto ou de conhecimento na produção de um bem tangível ou intangível, o que dificulta encaixar locação nessa concepção. Outro grande problema a respeito da incidência do ISSQN está relacionado ao fornecimento de mercadorias com adição de serviços, ou seja, como incidir o tributo quando existe uma mistura de matéria-prima e serviço no produto final. Nota-se, nessa situação, um conflito de incidência com o ICMS, de competência Estadual.

\section{Ação governamental e Gestão tributária do ISSQN}

No segundo semestre de 2005, o município de São Paulo editou a lei n. 14.042, regulamentada pelo decreto n. 46.598 , de 4 de novembro de 2005, alterando a legislação do ISSQN. Essa legislação acarretou novas obrigações tanto do prestador como do tomador de serviços, fatos geradores de ISSQN, visando coibir a prática de simulação de estabelecimentos em outros municípios de empresas de serviços que efetivamente operam na cidade de São Paulo. Segundo entendimento da administração, essa prática configura fraude 
contra a Administração Tributária do Município de São Paulo, causando sérios prejuízos ao erário público. Além disso, caracterizaria concorrência desleal, prejudicando os contribuintes regularmente estabelecidos no Município de São Paulo.

A vantagem obtida pela simulação de domicílio estaria diretamente relacionada à tão difundida guerra fiscal, que se manifestou, também, na esfera municipal por meio da prática de alíquotas diferenciadas, ${ }^{5}$ ou seja, reduzidas a tal ponto, que levaria muitas empresas de serviços que operam em municípios de maior alíquota a usar o expediente da simulação de domicílio.

A finalidade do estudo é analisar de que maneira as novas obrigações assumidas pelos prestadores e tomadores influenciam a arrecadação do ISSQN. Para atingir esse objetivo, serão utilizados modelos e ferramentais estatísticos para testar a significância estatística pela comparação de dois períodos, antes e após a implementação da legislação. A identificação do instante em que ocorre a transição de um período para o outro tem como base janeiro de 2006, ou seja, dois meses após o decreto que regulamentou a Lei n. 14.042. Considera-se razoável adotar esse intervalo de tempo entre a legislação e o ponto de transição em virtude dos efeitos de retardo que impedem uma resposta instantânea às exigências da nova legislação. De qualquer forma, uma simples observação do comportamento da arrecadação, nesse período, também permite eleger o ponto de transição com boa margem de segurança.

A Lei $n$. 14.042, em seu artigo $2^{\circ}$, obriga o prestador de serviços que emitir nota fiscal de serviços autorizada por outro município para tomador estabelecido em São Paulo, referente aos serviços de determinados itens descritos na Lei n. 13.701/03, ${ }^{6}$ proceder sua inscrição em cadastro da Secretaria Municipal de Finanças.

O parágrafo 20 , do mesmo artigo, cria a obrigação do tomador de serviços das empresas, com as características anteriores, a reter o valor devido do ISS quando, consultado o cadastro da Secretaria Municipal de Finanças, a prestadora não tiver sua inscrição regularizada.

Após o implemento da lei, foi editado o decreto n. 46.598, de 4 de novembro de 2005, que passou a regulamentar 0 disposto nos artigos 9o- $\mathrm{A}$ e 9o- $\mathrm{B}$ da Lei $\mathrm{n}$. 13.701, de 24 de dezembro de 2003, com alterações da Lei n. 14.042 e a portaria SF n. 101, de 7 de novembro de 2005, dispondo sobre o cadastro que o prestador fora do município deve efetuar frente à Secretaria Municipal de Finanças.

Ficaclaro o objetivo daimplementação dessa legislação ao observar que o principal fator de arrecadação está diretamente vinculado ao tomador de serviços, que deve proceder a retenção do tributo no caso de o prestador não estar devidamente cadastrado junto à administração pública. Existe, também, a tendência de que os prestadores com situação cadastral irregular procedam sua regularização perante a administração municipal, passando a recolher o ISS para o Município.

Com base nessa ótica, a análise do incremento da arrecadação, por conta dessa ação governamental, deve se focar, principalmente, nos tomadores e no comportamentodelesapósaimplementação da legislação. Assim foram verificadas as 
Mauro Maia Laruccia, Mamerto Granja Garcia, Elisabete Adami Pereira dos Santos, Arnaldo José França Mazzei Nogueira

arrecadações do ISSQN para dois grupos de serviços tomados: aqueles serviços que devem observar a Lei n. 14.042, ou seja, os tomadores têm de verificar o cadastro das empresas que the prestam serviços, e aqueles serviços não contemplados na lei. Nesse caso, os tomadores não necessitam verificar o cadastro das empresas que Ihe prestam serviços. Esses grupos estão discriminados no Quadro 1 a seguir.

Devem proceder sua inscrição em cadastro da Secretaria Municipal de Finanças

Servicos: de informática e congêneres, de pesquisas e desenvolvimento de qualquer natureza, prestados mediante locaçăo, cessảo de direito de uso e congêneres, de saúde, assistência médica e congêneres, de medicina e assistência veterinária e congêneres, de cuidados pessoais, estética, atividades físicas e congêneres, relativos a engenharia, arquitetura, geologia, urbanismo, construçäo civil, manutenção, limpeza, meio ambiente, saneamento e congéneres, de educação, ensino, orientaçäo pedagógica e educacional, instrução, treinamento e avaliação pessoal de qualquer grau ou natureza, relativos a hospedagem, turismo, viagens e congêneres, de intermediaçäo e congéneres, escolta, inclusive de veículos e cargas, produçăo, mediante ou sem encomenda prévia, de eventos, espetáculos, entrevistas, shows, ballet, danças, desfiles, bailes, teatros, óperas, concertos, recitais, festivais e congéneres, relativos à fonografia, fotografia, cinematografia e reprografia, relativos a bens de terceiros, relacionados ao setor bancário ou financeiro, inclusive aqueles prestados por instituiçoes financeiras autorizadas a funcionar pela Uniâo ou por quem de direito, de apoio técnico, administrativo, jurídico, contábil, comercial e congêneres, de regulaçăo de sinistros vinculados a contratos de seguros; inspeção e avaliaçäo de riscos para cobertura de contratos de seguros; prevenção e gerẻncia de riscos seguráveis e congêneres, de distribuiçäo e venda de bỉhetes e demais produtos de loteria, bingos, cartỏes, pules ou cupons de apostas, sorteios, prêmios, inclusive os decorrentes de titulos de capitalizaçäo e congêneres, de registros públicos, cartorários e notariais, de exploraçäo de rodovia, de programação e comunicaçäo visual, desenho industrial e congêneres, de chaveiros, confeç̧äo de carimbos, placas, sinalizaçăo visual, banners, adesivos e congêneres, funerários, de coleta, remessa ou entrega de correspondèncias, documentos, objetos, bens ou valores, inclusive pelos correios e suas agéncias franqueadas; courrier e congéneres, de assistência social, de avaliação de bens e serviços de qualquer natureza, de biblioteconomia, de biologia, biotecnologia e química, técnicos em edificações, eletrônica, eletrotécnica, mecânica, telecomunicaçôes e congéneres, de desenhos técnicos, de desembaraço aduaneiro, comissários, despachantes e congêneres, de investigaçôes particulares, detetives e congèneres, de reportagem, assessoria de imprensa, jomalismo e relaçôes públicas, de meteorologia, de artistas, atletas, modelos e manequins, de museologia, de ourivesaria e lapidação, relativos a obras de arte sob encomenda.

Dispensados da inscrição em cadastro da Secretaria Municipal de Finanças

Serviços: de cessâo de andaimes, palcos, coberturas e outras estruturas de uso temporário, de medicina e assisténcia veterinária e congêneres, execuçăo, por administraçäo, empreitada ou subempreitada, de obras de construção civil, hidráulica ou elétrica e de outras obras semelhantes, inclusive sondagem, perfuraçăo de poços, escavação, drenagem e irrigação, terraplanagem, pavimentação, concretagem e a instalaçăo e montagem de produtos, peças e equipamentos (exceto o fornecimento de mercadorias produzidas pelo prestador de serviços fora do local da prestação dos serviços, que fica sujeito ao ICMS), demoliçäo, reparaçä̉o, conservação e reforma de edifícios, estradas, pontes, portos e congéneres (exceto o formecimento de mercadorias produzidas pelo prestador dos serviços, fora do local da prestaçäo dos serviços, que fica sujeito ao ICMS), varriçäo, coleta, remoçẳo, incineraçäo, tratamento, reciclagem, separação e destinaçáo final de lixo, rejeitos e outros residuos quaisquer, limpeza, manutenção e conservaçẩo de vias e logradouros públicos, imóveis, chaminés, piscinas, parques, jardins e congẻneres, decoraçâa e jardinagem, inclusive corte e poda de árvores, controle e tratamento de efluentes de qualquer natureza e de agentes físicos, químicos ou biológicos, florestamento, reflorestamento, semeadura, adubaçăo e congếneres, escoramento, contençắo de encostas e serviços congéneres, limpeza e dragagem de rios, portos, canais, baías, lagos, lagoas, represas, açudes e congêneres, acompanhamento e fiscalizaçảo da execução de obras de engenharia, arquitetura e urbanismo, de guarda, estacionamento, armazenamento, vigiláncia e congếneres, de diversöes, lazer, entretenimento e congéneres, de transporte de natureza municipal, fornecimento de máo de obra, mesmo em caráter temporário, inclusive de empregados ou trabalhadores, avulsos ou temporários, contratados pelo prestador de serviço e planejamento, organização e administraçăo de feiras, exposiçōes, congressos e congêneres,

Quadro 1. Descrição dos serviços obrigados e dos dispensados da inscrição em cadastro da Secretaria Municipal de Finanças.

Fonte: Anexo Único integrante do Decreto n. 46.598, de 4 de novembro de 2005, artigos 10 e 20 e lista do artigo 10 da Lei n. 13.701/2003, legislação do Município de São Paulo. 
Essa arrecadação foi analisada ao longo de um período que engloba dois momentos: os meses que antecederam a vigência da Lei e os meses posteriores a ela para cada grupo.

\section{Procedimentos de análise}

\subsection{Conjunto de dados}

Objeto de análise deste artigo, o conjunto de dados utilizado aqui advém do sistema denominado Quadro contábil, administrado pela empresa de economia mista ${ }^{7}$ de Processamento de Dados do Município de São Paulo (Prodam). Nesse sistema, os dados do ISSQN são organizados por grupos de serviços ${ }^{8}$ e, dentro de cada um, são dispostos por códigos de serviços ${ }^{9} \mathrm{e}$, além disso, em cada grupo, existe uma categorização de códigos no que se refere às categorias tomadores de serviços ${ }^{10}$ e prestadores de serviços. ${ }^{11} \mathrm{~A}$ descrição detalhada dos grupos e códigos de serviço permite uma análise específica para cada atividade ou grupo de atividades, o que possibilita observar aquelas que são influenciadas por uma ação de intervenção governamental em especial.

No caso específico do ISSQN, a ação governamental, por meio da Lei n. 14.042, afetou alguns códigos de serviço, os quais foram identificados e analisados separadamente. Quanto ao ITBI-IV, os dados correspondem à arrecadação mensal do tributo apresentada no sistema orçamentário da Prefeitura do Município de São Paulo (PMSP).

\subsection{Modelagem estatística}

Os modelos estatísticos usados neste artigo baseiam-se em modelos de regressão linear combinados com a aplicação de variáveis qualitativas binárias, também conhecidas como variáveis dummies, as quais podem assumir somente dois valores: 0 ou 1 . 0 objetivo das variáveis binárias é verificar se, estatisticamente, é possível afirmar que a ação governamental afetou a arrecadação do ISS. Os modelos estatísticos têm como base o comportamento da arrecadação em dois momentos: antes e após a ação governamental. A seguir, é aplicado um teste estatístico para o comportamento da arrecadação nos dois momentos, ou seja, se há diferenças estatisticamente significativas $^{12}$ entre os dois momentos quanto à arrecadação.

Para modelar a intervenção, usa-se aqui a regressão linear por partes descontínua (GUJARATI, 2000), a qual consiste em dois segmentos lineares: um correspondente ao período anterior à intervenção e outro posterior a ela. Esse modelo pode ser representado pela expressão:

$$
Y_{i}=\beta_{01}+\beta_{1} t_{i}+\beta_{02} D_{i}+\beta_{2}\left(t_{i}-t\right) D_{i}+u_{i}
$$

Onde temos:

$\mathbf{Y}_{\mathbf{i}}=$ arrecadação do mês

$\mathbf{t}_{\mathbf{i}}=$ mês da arrecadação

$\mathbf{t}=$ instante limiar (momento da implantação da ação ou intervenção)

$\boldsymbol{\beta}_{1}$ e $\boldsymbol{\beta}_{2}$, coeficientes de inclinação

$\boldsymbol{\beta}_{01}$ e $\boldsymbol{\beta}_{02}$, definem os interceptos (cortam o eixo $Y$ )

$\mathbf{u}_{\mathbf{i}}=$ termo aleatório

$\mathbf{D}_{\mathbf{i}}=0$ ou 1 correspondendo à variável dummy, que indica se o período é antes da ação (0) ou após ela (1). 
Optar pelo uso desse modelo implica algumas considerações importantes quando se trabalha com séries históricas. A mais significativa refere-se ao fato de que a análise leva em conta dois fenômenos das séries temporais: tendência e mudança de nível (média) em um instante específico, tratando-se, portanto, de uma simplificação, pois, a rigor, uma série histórica sofre influência de outros fatores que implicam movimentos não só de tendência e mudança de nível, mas também de sazonalidade. $O$ parâmetro $\beta_{2}$ indica se houve mudança na tendência, ou seja, se a taxa de crescimento da arrecadação do tributo sofreu alguma alteração. A mudança de nível é captada pelo modelo através do parâmetro $\beta_{02}$, ou seja, sendo este significativo, indicará o salto (mudança de nível) na série da arrecadação. Quanto à sazonalidade, teoricamente é possível fazer uso da regressão com variáveis dummies para modelar a sazonalidade, entretanto, como medida de simplificação, não será usado esse recurso porque 0 comportamento sazonal é bem regular ao longo do ano, ${ }^{13}$ seguindo as mudanças de nível e tendência, e, para comparação com a atividade econômica, basta a análise do nível e da tendência da arrecadação.

A Figura 2 ilustra a ideia do modelo e, por meio dela, é possível notar que o teste estatístico deve verificar se os parâmetros ${ }^{14} \beta_{02}$ e $\beta_{2}$ são significativos, ou seja, diferentes de zero. Dizer que o parâmetro $\beta_{02}{ }^{15}$ é diferente de zero mostra que a intervenção provocou um "salto" na arrecadação a partir do momento de seu implemento, indicado por $t$, atingindo um novo patamar. Quanto ao parâmetro $\beta_{2}$, ser diferente de zero indica que, além do salto, pode haver uma mudança na taxa de crescimento da arrecadação, ou seja, essa taxa seria mais acentuada.

Figura 2 - Representação esquemática do modelo linear por partes descontínuas.

\section{Y: Arrecadação}

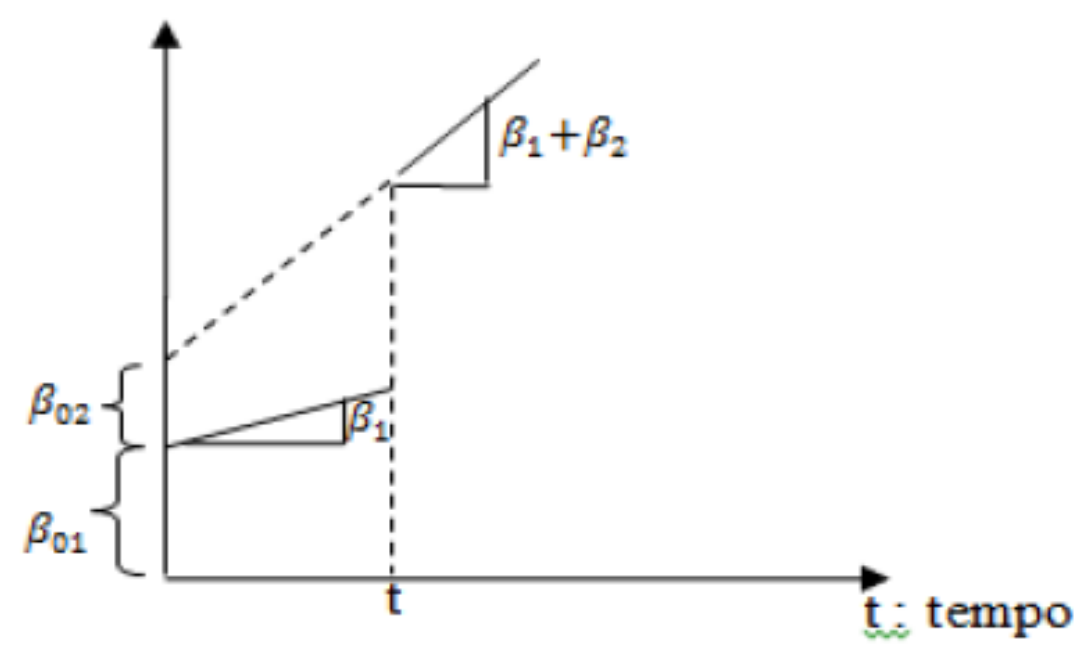

Fonte: elaborado pelos autores. 
O gráfico da Figura 3 mostra a evolução da arrecadação do ISS para os dois períodos separados em razão das atividades que devem ou não observar a lei 14.042. Podese notar claramente o comportamento da arrecadação nos períodos antes e após a ação governamental. A arrecadação dos dois tipos de tomadores ${ }^{16}$ mantinha-se no mesmo patamar de valores arrecadados até meados de janeiro de 2006 e, a partir desse momento, é possível notar o "descolamento" dos dois grupos de tomadores. Observase também que, mensalmente, houve um acréscimo aproximado de $\mathrm{R} \$ 20$ milhões na arrecadação no grupo de tomadores incluídos na ação governamental. Assim, no período de 12 meses, tem-se a expectativa de um acréscimo de aproximadamente $\mathrm{R} \$$ 240 milhões na arrecadação do ISS. Com base nesses dados, resta agora confirmar esse comportamento por meio do teste estatístico adequado.

Figura 3 - Evolução da arrecadação do ISS para o grupo de tomadores (retenção na fonte) incluídos e excluídos da Lei n. 14.042/05, mostrando o momento em que houve o "descolamento" das séries históricas.

\section{Lei 14.042 Tomadores Incluidos x Excluidos}

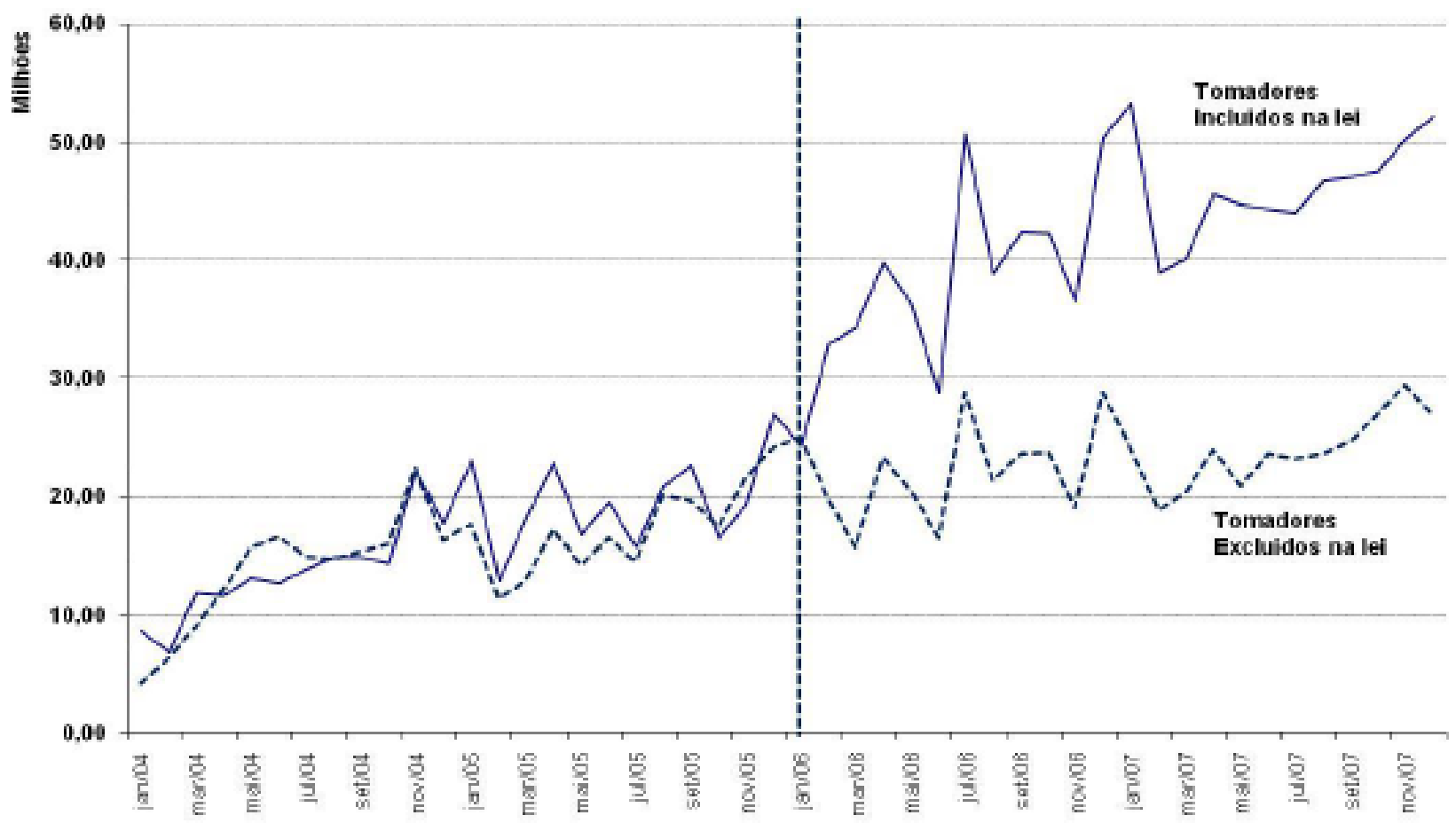

Fonte: Quadro Contábil 
Para dar início à análise estatística, procedeuse o isolamento dos tomadores de serviços que devem observar a Lei n. 14.042/05. O resultado do isolamento é mostrado no gráfico da Figura 3, que mostra a evolução da arrecadação do ISS em relação aos tomadores referentes à arrecadação total.

O gráfico da Figura 5 mostra a evolução da arrecadação do conjunto de atividades vinculadas aos prestadores. O objetivo é analisar o impacto da ação governamental também nos prestadores (ISS próprio) por meio do mesmo teste aplicado aos tomadores. Com base nos valores gerados nesses gráficos, foram realizados os testes estatísticos para verificar a significância dos parâmetros envolvidos, ou seja, se $\beta_{01}, \beta_{1}, \beta_{02}, \beta_{2}$ são significativos.

Para a realização desses testes estatísticos, foi utilizado o Excel, ${ }^{17}$ tendo em vista que esse programa possui recursos suficientes para adaptação do modelo proposto.

Figura 4 - Evolução da arrecadação total do ISS do grupo de tomadores (retenção na fonte).

ISS Tomador

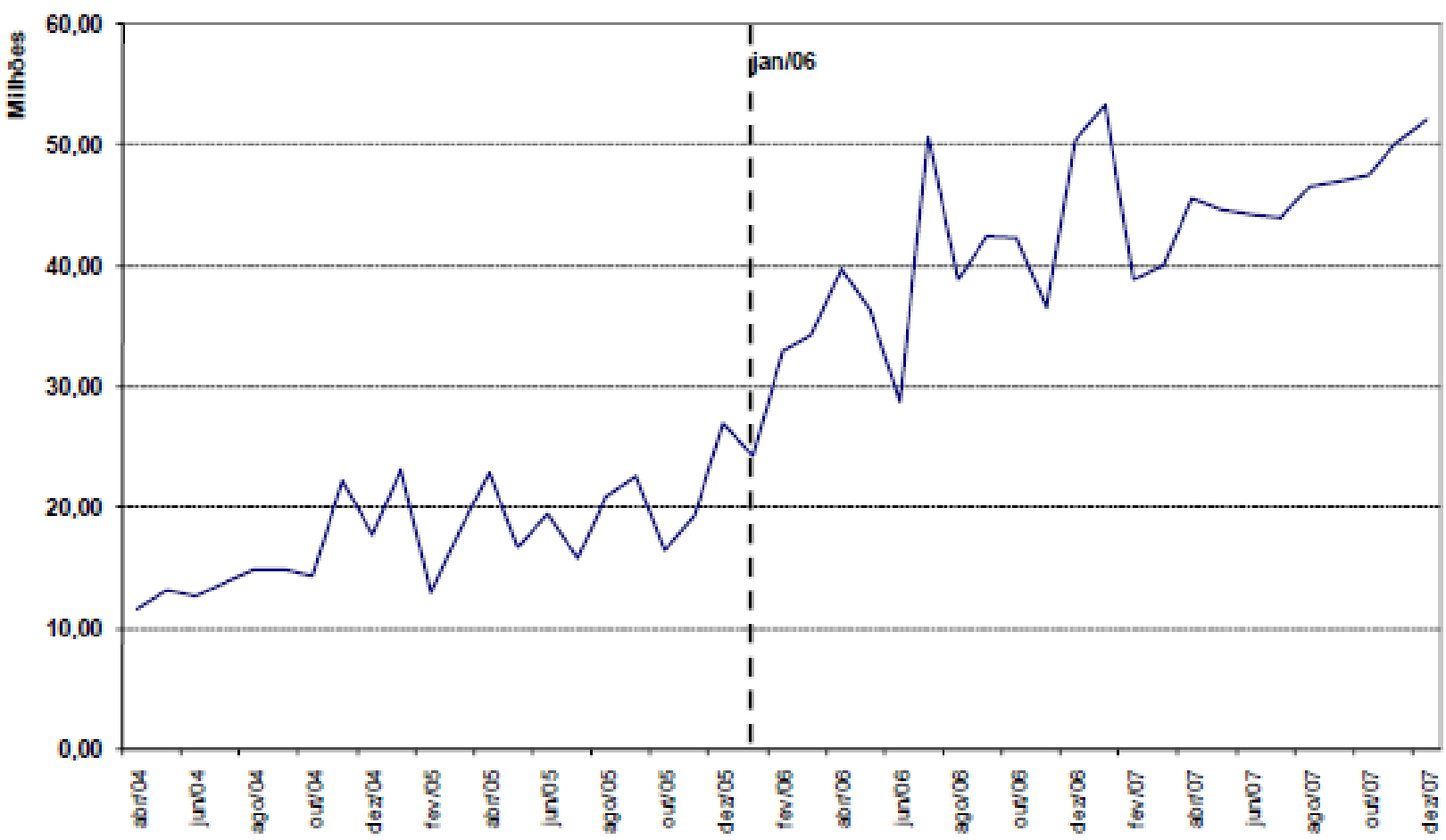

Fonte: Quadro Contábil 
Figura 5 - Evolução da arrecadação total do ISS para os prestadores.

ISS Prestador

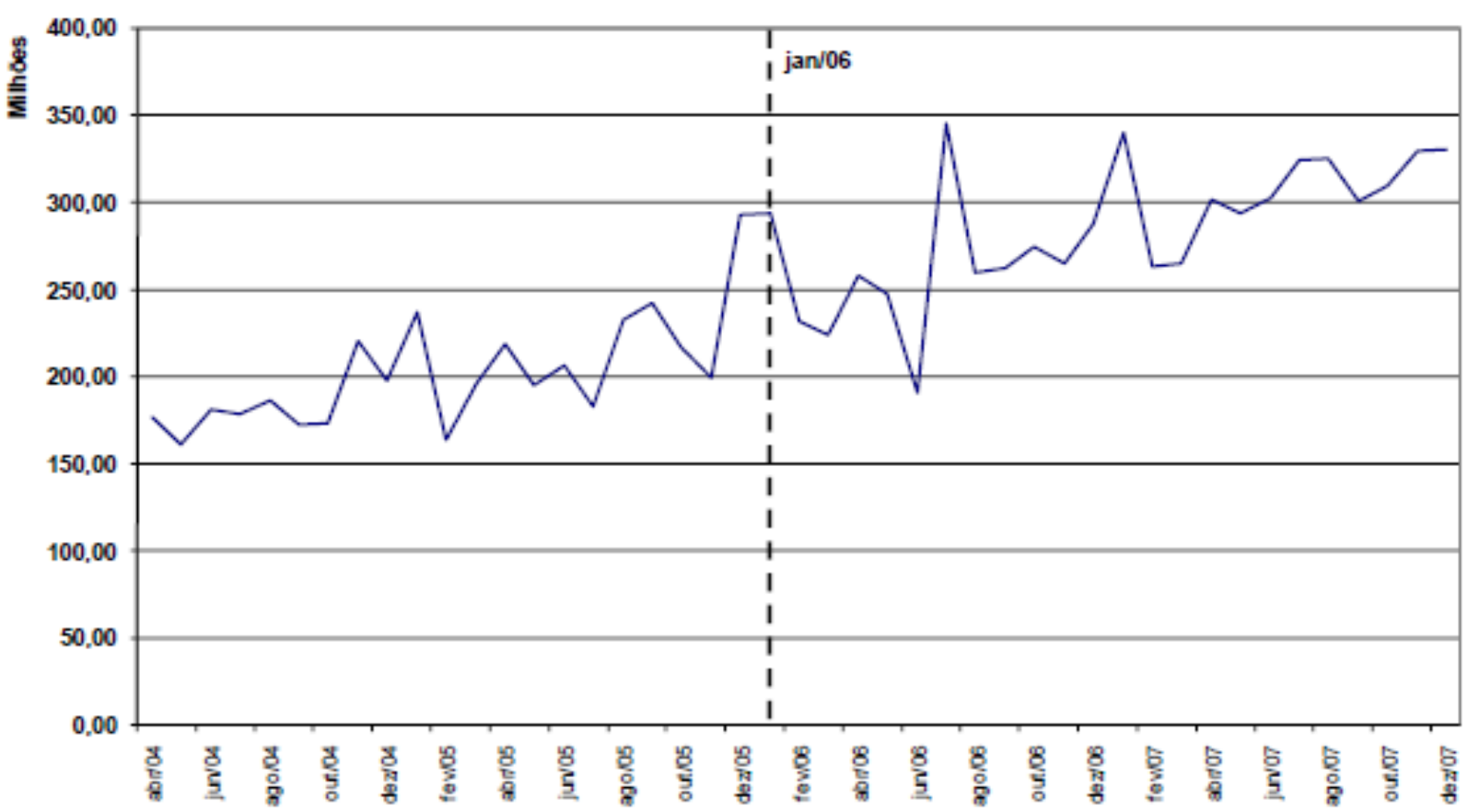

Fonte: Quadro Contábil

\section{Análise e discussão dos resultados}

A primeira análise refere-se ao caso tomadores, ou seja, há interesse em verificar se houve mudanças no comportamento da arrecadação do ISS no grupo tomadores a partir de janeiro de 2006. Nesse caso, buscou-se um teste estatístico para verificar a significância dos parâmetros $\beta_{01}, \beta_{1}, \beta_{02}, \beta_{2}$. O resultado da regressão usando a equação econométrica proposta é mostrado na Tabela 1, em que é possível constatar que, dentro de um nível de significância de $5 \%$, somente o parâmetro $\beta_{2}$ não apresentou significância estatística ( $p$-valor ${ }^{18}$ de 0,587$)$. Assim, o teste indica que houve um salto na arrecadação $\left(\beta_{2}\right.$ diferente de zero), ou seja, efeito da ação governamental sobre a arrecadação do tributo de forma incisiva. O fato de o parâmetro $\beta_{2}$ não apresentar significância estatística mostra que, apesar do salto, a taxa de crescimento da arrecadação se manteve estável em aproximadamente $\mathrm{R} \$$ $550.000,00$ a cada mês. 
Tabela 1. Resultado da regressão para os tomadores.

\begin{tabular}{|c|c|c|c|c|c|}
\hline \multicolumn{2}{|c|}{ Estalistica de regrassio } & & & & \\
\hline R matiplo & 0,96 & & & & \\
\hline R-Qundrado & 0,92 & & & & \\
\hline R-quadrado ajustado & 0,92 & & & & \\
\hline Eño padrāo & $4.112 .484,94$ & & & & \\
\hline Observaçōes & 48,00 & & & & \\
\hline \multicolumn{6}{|l|}{ ANOVA } \\
\hline & $\mathrm{gl}$ & so & MO & $F$ & F de signifikcapấio \\
\hline Rogressāo & 3,00 & $8.973 .744 .947 .701 .600,00$ & $2.991 .248 .315 .900 .500,00$ & 176,87 & $1,46016 \mathrm{E}-24$ \\
\hline Resiovo & 44,00 & $744.151 .423 .929 .506,00$ & $16.912532 .362 .034,30$ & & \\
\hline \multirow[t]{2}{*}{ Total } & 47,00 & $9.717 .896 .371 .631 .190,00$ & & & \\
\hline & Coeficiontes & Eno padräo & Statt & vajarfo & \\
\hline$\beta_{01}$ & $9.714 .809,84$ & $1.695 .620,98$ & 5,73 & 0,000001 & \\
\hline$\beta_{1}$ & $551.593,40$ & $114.059,81$ & 4,84 & 0,000017 & \\
\hline$\beta_{01}$ & $11.721 .838,03$ & $2.385 .737,48$ & 4,91 & 0,000013 & \\
\hline $\boldsymbol{\beta}_{2}$ & $94.402,45$ & 172399,62 & 0,55 & 0,596748 & \\
\hline
\end{tabular}

Fonte: elaborado pelos autores.

A segunda análise está voltada para a que os parâmetrosnão foram significativos arrecadação dos prestadores, ou seja, se (p-valores 0,473 e 0,713, respectivamente). a ação governamental afetou, de alguma Com base nesse resultado, o teste indica que maneira, o comportamento da arrecadação não houve salto significativo na arrecadação nesse conjunto. A Tabela 2 mostra o tampouco mudança na taxa de crescimento resultado da regressão. Pode-se observar dessa arrecadação.

Tabela 2 - Resultado da regressão para os prestadores.

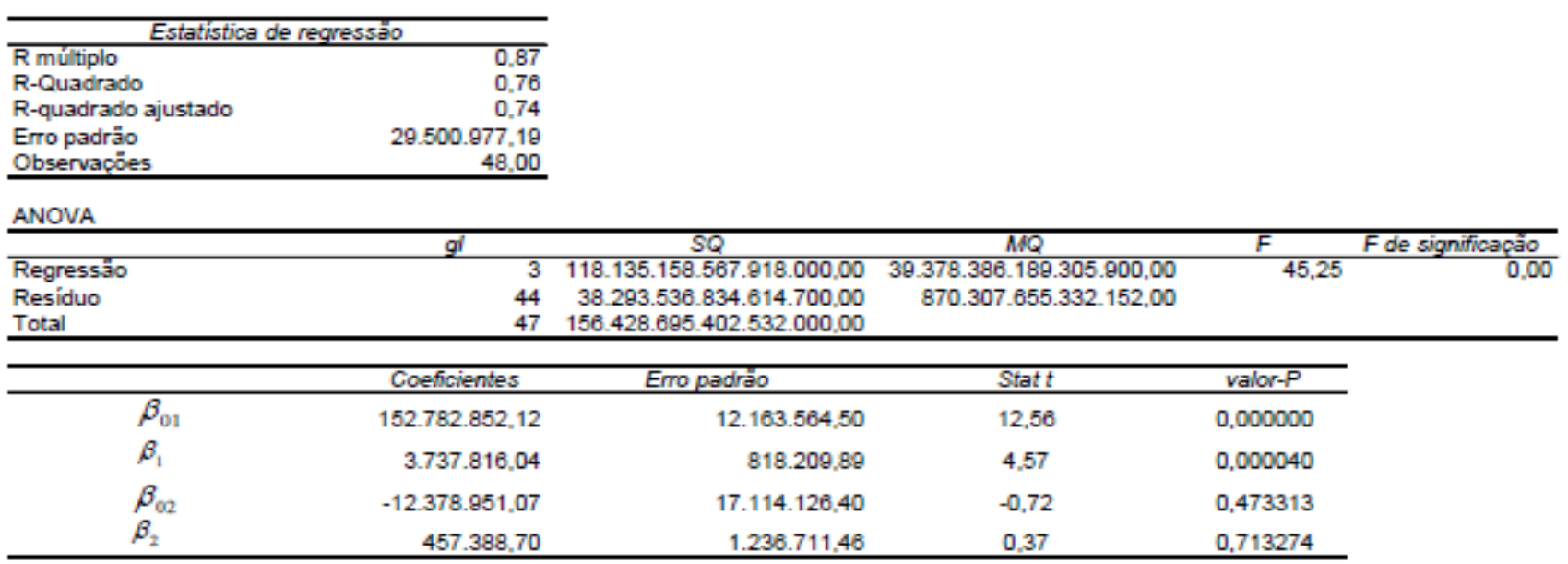

Fonte: elaborado pelos autores. 
A Tabela 3 mostra a evolução do PIB no Município de São Paulo e da arrecadação do ISSQN, em valores correntes, no período de 2000 a 2010. Têm-se os valores nominais do PIB e do ISSQN, os quais incorporam os efeitos da inflação e do crescimento econômico. Essa série permite constatar que o PIB cresceu nominalmente $193,9 \%$ no período de 2000 a 2010 e o ISSQN $384,6 \%$, ou seja, $64,9 \%$ acima do PIB nominal, o que demonstra efeitos na arrecadação do imposto que vão além do crescimento econômico. Há fortes indícios de que as ações governamentais influenciaram a arrecadação, tendo como principal medida o cadastro obrigatório dos prestadores de outros municípios, mitigando a simulação de endereços dos estabelecimentos.

Tabela 3. Comparativo dos valores correntes e variação nominal do PIB e da arrecadação do ISSQN do Município de São Paulo no período de 2000 a 2010. Fonte: IBGE e Tesouro Nacional.

\begin{tabular}{rcrrr}
\hline Ano & \multicolumn{1}{c}{ PIB } & Var. Nominal(\%) & Arrec. ISSQN & Var. Nominal(\%) \\
\hline 2000 & $160.285 .568,00$ & 6,2 & $1.673 .196 .549,36$ & 16,7 \\
2001 & $177.991 .546,00$ & 11,0 & $1.847 .857 .499,21$ & 10,4 \\
2002 & $187.953 .256,00$ & 5,6 & $1.973 .615 .890,75$ & 6,8 \\
2003 & $209.555 .133,00$ & 11,5 & $2.146 .613 .971,81$ & 8,8 \\
2004 & $225.170 .382,00$ & 7,5 & $2.592 .542 .001,78$ & 20,8 \\
2005 & $261.455 .917,00$ & 16,1 & $3.143 .383 .522,45$ & 21,2 \\
2006 & $282.892 .455,00$ & 8,2 & $4.084 .718 .925,40$ & 29,9 \\
2007 & $323.154 .666,00$ & 14,2 & $4.781 .513 .008,93$ & 17,1 \\
2008 & $356.980 .045,00$ & 10,5 & $5.604 .131 .677,41$ & 17,2 \\
2009 & $389.284 .929,00$ & 9,0 & $5.907 .002 .309,86$ & 5,4 \\
2010 & $443.600 .102,00$ & 14,0 & $6.946 .539 .609,65$ & 17,6 \\
\hline
\end{tabular}

Fonte: elaborado pelos autores.

\subsection{Resultado da Ação governamental e da Gestão tributária do ITBI-IV}

O decreto municipal n. 46.228 , de 23 de agosto de 2005, estabelece o regulamento do ITBI-IV com destaque especial para o artigo 12, o qual define a Declaração de Transação Imobiliária (DTI).

Art. 12. A Declaração de Transação Imobiliária (DTI) é o instrumento pelo qual o contribuinte ou responsável informa à Administração Tributária a ocorrência do fato gerador do ITBI-IV.

$\S 1^{\circ} \mathrm{A}$ Declaração deverá ser feita até a data em que se efetivar o ato ou contrato sobre o qual incide.

$\S 2^{\circ}$ A omissão de informações ou a prestação de declarações falsas na Declaração de Transação Imobiliária configuram hipótese de crime contra a ordem tributária prevista no artigo 20 da Lei n. 8.137, de 27 de dezembro de 1990, sem prejuízo das demais sanções penais e administrativas cabíveis.

$\S 3^{\circ} \bigcirc$ formulário da Declaração de Transação Imobiliária será disponibilizado pela Secretaria Municipal de Finanças, por meio da internet, no endereço eletrônico da Prefeitura do Município de São Paulo.

$\S 4^{\circ} \mathrm{O}$ preenchimento da Declaração de Transação Imobiliária será feito 
consoante instruções constantes de Portaria da Secretaria Municipal de Finanças e disponibilizadas pela internet.

Esse decreto passou a vigorar na data de sua publicação, produzindo efeitos a partir da portaria 81 da Secretaria Municipal de Finanças, com vigência a partir de 5 de setembro de 2005. A importância da ação governamental por meio desse dispositivo legal quanto à arrecadação do ITBI-IV está no fato de que reduziu drasticamente a possibilidade de simulação nas transações imobiliárias. A DTI inovou a forma de os contribuintes declararem as transações imobiliárias, impondo a obrigatoriedade da declaração dos dados da transação pela internet por meio de um sistema residente no Portal da Prefeitura da Cidade de São Paulo.

Antes, era utilizada uma guia de papel a ser preenchida manualmente, permitindo que o contribuinte declarasse livremente o valor da transação, base de cálculo do ITBI-IV. Essa liberdade ficou limitada, pois o novo sistema da DTI de declaração eletrônica localizado no Portal da Prefeitura passou a definir, internamente, o valor atribuído, aquele considerado como valor de mercado para o imóvel. ${ }^{19}$

A legislação do ITBI-IV definia que, em nenhuma hipótese, o valor a ser utilizado, como base de cálculo, poderia ser inferior ao valor venal do imóvel aplicado para fins de incidência do IPTU. É fato notório, entretanto, que a maioria dos imóveis no Município de São Paulo apresenta o valor venal utilizado como base de cálculo para o IPTU, definido por lei por meio da Planta Genérica de Valores (PGV), muito abaixo de seu valor de mercado. Na época anterior a DTI, alguns contribuintes, cientes desse fato, simulavam o valor da transação, adotando preço próximo ao valor venal do IPTU, inclusive valores abaixo deste último.

A introdução da DTI trouxe uma novidade: um sistema de cálculo do valor de mercado do imóvel (valor atribuído). Sempre que o valor da transação fosse inferior ao atribuído, recusava-se o valor declarado da transação e adotava-se o atribuído. Foi exatamente nesse ponto que a ação governamental surtiu efeito, aumentando de forma considerável a arrecadação do ITBI-IV sem qualquer majoração do tributo. Houve muitas contestações a respeito da legalidade desse decreto. Tentou-se desqualificá-lo afirmando que houve majoração do tributo e que, nesse caso, seria necessária a aprovação de uma lei específica com vigência a partir do primeiro dia do exercício seguinte. Outra linha de contestação afirmava que havia conflito na adoção de um valor venal para o IPTU e outro para o ITBI-IV, o valor atribuído.

Seguiram-se outras contestações, tal como a que alegava que havia interferência na livre negociação de mercado quando o município impunha ao contribuinte um valor atribuído que não correspondia ao valor efetivo da transação em muitos casos. Isso ocorre quando o valor atribuído é superior ao da transação sem qualquer indício de simulação. Nessa situação, o que acontece normalmente é uma situação díspar de mercado, ou seja, não houve uma condição normal de negociação, o que equivale a dizer que, por alguma razão inerente aos negociantes, o preço estabelecido estava abaixo do valor de mercado.

Dessa forma, a administração tributária 
entende que uma transação com valor abaixo do atribuído não implica, necessariamente, base de cálculo do tributo. Não significa, entretanto, que o contribuinte deve sempre acatar o valor atribuído, pois existem situações que reduzem o valor de mercado de um imóvel em curto intervalo de tempo como, por exemplo, a instalação de uma favela na região. Prevendo essas situações, a administração tributária permite que o contribuinte conteste, administrativamente, o valor atribuído por meio de uma reclamação tributária para avaliação especial. Mesmo que ela seja indeferida pela administração, o contribuinte pode recorrer à esfera judicial.

Seguindo o mesmo procedimento adotado para o ISSQN, serão comparados dois períodos: um anterior ao implemento do Decreto n. 46.228/05 e a Portaria n. 81/05 e outro posterior, usando-se como momento de corte dois meses após a vigência da portaria, ou seja, a partir de dezembro de 2005, inclusive. O gráfico da Figura 6 mostra o comportamento da arrecadação do ITBIIV, em valores reais de dez/10, entre dez/95 e dez/10, usando-se como deflator o IPCA. Para melhor visualizar o efeito da ação governamental, foi incluída a média móvel de 12 meses, a qual permite suavizar os efeitos da sazonalidade na arrecadação. Foi incluída uma linha divisória entre os dois períodos propostos para análise.

Figura 6. Evolução da arrecadação mensal real do ITBI-IV e respectiva média móvel de 12 meses para os prestadores de serviços, período de dez/95 a jun/10.

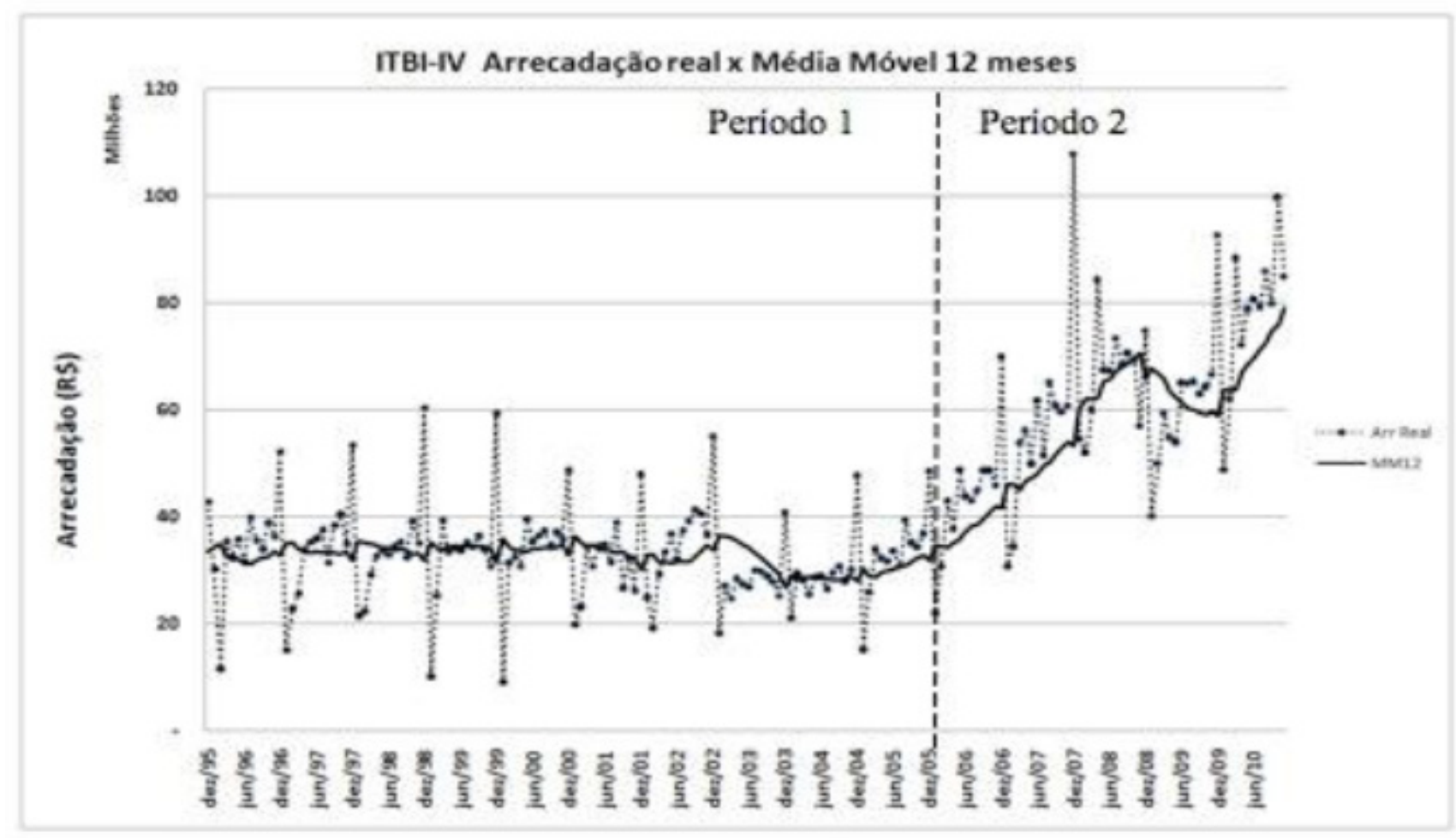

Fonte: Sistema orçamentário - PMSP. Deflator: IPCA. 
A partir do gráfico, pode-se observar que a arrecadação real do ITBI-IV praticamente não aumentou no período entre dez/95 a dez/05. Nota-se, por exemplo, que a arrecadação real no exercício 2003 chegou a patamares inferiores ao exercício 1996, o que indica o grau de estagnação do tributo, que permanece num patamar baixo até dez/05 e, a partir daí, entra num ciclo ascendente de crescimento somente interrompido em 2009, em razão dos efeitos da crise internacional. Tão logo a crise perde força, retoma o ritmo acelerado de crescimento em 2010.

Seria precipitado afirmar que esse crescimento se deve exclusivamente à ação governamental, pois é quase certo que conjunturas socioeconômicas participaram desse crescimento, entretanto, isolar esses efeitos demandaria uma análise mais aprofundada e foge do escopo deste trabalho.

A partir dos dados da arrecadação, nos períodos considerados, efetua-se a análise estatística do comportamento da arrecadação e avaliam-se os efeitos da ação governamental.

A análise de regressão focando os dois períodos de arrecadação real do ITBI-IV, o primeiro no período de dez/95 a dez/05 e o segundo de jan/06 a dez/10, forneceu o resultado mostrado na Tabela 4.0 ajuste dos dados ao modelo econométrico foi satisfatório, tendo em vista que o R-quadrado ajustado foi 0,699, ou seja, praticamente $70 \%$.A estatística $\mathrm{F}$ apresentou valor alto de significação em função do $p$-valor praticamente igual a zero. Assim, pode-se dizer que a regressão existe para um ou mais parâmetros.

Não foi encontrada significância estatística para o parâmetro $\beta$, o qual apresentou p-valor de 0,42 . Essa falta de significância já era esperada, pois no período 1 a arrecadação real do ITBI-IV permaneceu no mesmo patamar, ou seja, não apresentou taxa de crescimento real significativa. Todos os parâmetros restantes apresentaram significância estatística: $p$-valor de aproximadamente 0,01 para o parâmetro $\beta_{02}$ e de aproximadamente zero (alta significância estatística) para $\circ \beta_{2}$. 
Tabela 4. Resultado da regressão para a arrecadação real do ITBI-IV.

\begin{tabular}{lr}
\hline \multicolumn{2}{c}{ Estatística de regressão } \\
\hline R múltiplo & 0,839 \\
R-Quadrado & 0,704 \\
R-quadrado ajustado & 0,699 \\
Erro padrão & 10221660,68 \\
Observações & 181 \\
\hline
\end{tabular}

ANONA

\begin{tabular}{|c|c|c|c|c|c|}
\hline & $g l$ & SQ & $M Q$ & $\boldsymbol{F}$ & F de significaçäo \\
\hline Regressfo & 3 & $4,40308 \mathrm{E}+16$ & $1,46 / 69 \mathrm{E}+16$ & 140,4728152 & $1,35933 E-46$ \\
\hline Residuo & 177 & $1,84934 \mathrm{~F}+16$ & $1,04482 \mathrm{E}+14$ & & \\
\hline Total & 180 & $6,25242 E+16$ & & & \\
\hline
\end{tabular}

\begin{tabular}{lcccc}
\hline & Coeficientes & Erro padrõo & Stat t & valor $P$ \\
\hline$\beta_{a 1}$ & 34214928,78 & 1870063,209 & 18,29613492 & $1,15441 \mathrm{E}-42$ \\
$\beta_{1}$ & $-21402,05255$ & 26604,11762 & $-0,804463913$ & 0,422208299 \\
$\beta_{t D}$ & 8197431,533 & 3248703,381 & 2,523293317 & 0,012506767 \\
$\beta_{2}$ & 753698,9202 & 80709,14902 & 9,338457031 & $4,13844 \mathrm{E}-17$ \\
\hline
\end{tabular}

Fonte: elaborado pelos autores.

A existência de significância estatística para o parâmetro $\beta_{02}$ mostra que a arrecadação real do ITBI-IV mudou de patamar (média) a partir de dez/05 (período 2) com um salto, em termos reais, de aproximadamente $\mathrm{R} \$ 8$ milhões. $A$ alta significância estatística do parâmetro $\beta_{1}$ indica que a arrecadação do ITBI-IV passou a apresentar taxas significativas de crescimento a partir de dez/05, algo próximo de $\mathrm{R} \$ 750$ $\mathrm{mil} / \mathrm{mês}$. Assim, pode-se inferir que algo aconteceu a partir de dez/05 que não se explica simplesmente pela conjuntura econômica. A ação governamental na arrecadação do ITBIIV apresentou resultados significativos.

Seria precipitado afirmar que esse crescimento se deve exclusivamente à ação governamental, pois é quase certo que conjunturas econômicas contribuíram para isso. A variação nominal de vendas de imóveis residenciais no Município de São Paulo, no período de 2005 a 2010, foi de 133,4\% (Secovi, 2011). Nesse mesmo período, o PIB paulistano apresentou crescimento nominal de $97,0 \%$ e a arrecadação do ITBI-IV um incremento nominal de $266,9 \%$, praticamente o dobro do crescimento nominal das vendas de imóveis residenciais.

ATabela 5mostraa evolução daarrecadação do ITBI-IV em comparação com a evolução nominal do PIB do Município de São Paulo no período de 2000 a 2010. Nesse período, o PIB cresceu $193,9 \%$ e a arrecadação do ITBI-IV 384,5\%, o que representa $64,9 \%$ acima do PIB nominal, número idêntico ao encontrado para o ISS. 
Tabela 5. Comparativo dos valores correntes e variação nominal do PIB e da arrecadação do ITBIIV do Município de São Paulo no período de 2000 a 2010.

\begin{tabular}{rrrrr}
\hline Ano & PIB & Var. Nominal(\%) & Arrec. ITBI-IV & Var. Nominal(\%) \\
\hline 2000 & $160.285 .568,00$ & 6,19 & $209.928 .519,28$ & 7,5 \\
2001 & $177.991 .546,00$ & 11,05 & $208.969 .179,11$ & $-0,5$ \\
2002 & $187.953 .256,00$ & 5,60 & $254.627 .117,40$ & 21,8 \\
2003 & $209.555 .133,00$ & 11,49 & $228.919 .566,46$ & $-10,1$ \\
2004 & $225.170 .382,00$ & 7,45 & $257.910 .291,42$ & 12,7 \\
2005 & $261.455 .917,00$ & 16,11 & $309.320 .017,94$ & 19,9 \\
2006 & $282.892 .455,00$ & 8,20 & $426.706 .479,51$ & 37,9 \\
2007 & $323.154 .666,00$ & 14,23 & $581.827 .921,47$ & 36,4 \\
2008 & $356.980 .045,00$ & 10,47 & $707.780 .896,24$ & 21,6 \\
2009 & $389.284 .929,00$ & 9,05 & $683.379 .630,66$ & $-3,4$ \\
2010 & $443.600 .102,00$ & 13,95 & $946.348 .225,20$ & 38,5 \\
\hline
\end{tabular}

Fonte: IBGE e Tesouro Nacional

\section{Considerações finais}

Com base nas análises estatísticas efetuadas, é possível concluir que houve efeito da ação governamental na arrecadação do ISSQN quando se isolam as atividades e os contribuintes que estão diretamente vinculados à ação. $\mathrm{O}$ modelo utilizado mostrou que houve salto na arrecadação, ou seja, foi atingido um novo patamar, o qual se manteve, ao menos estatisticamente, sem mostrar sinais de mudança na taxa de crescimento da arrecadação.

Ficou demonstrado que, no período de 2000 a 2010, o aumento da arrecadação do ISSQN foi muito além da expansão econômica do Município de São Paulo, com crescimento nominal de $64,9 \%$ acima do PIB nominal. A maior parcela dessa arrecadação pode ser atribuída à obrigatoriedade do cadastro de prestadores de serviços de outros municípios conjuntamente com $\mathrm{o}$ aprimoramento da fiscalização do tributo por meio da inteligência fiscal. O restante é devido a efeitos residuais que podem ser explicados pela dinâmica da economia do setor de serviços, a qual é ligeiramente distinta da economia global do município.

A ação governamental voltada para a arrecadação do ITBI-IV mostrou-se eficaz, uma vez que elevou a arrecadação a um novo patamar, com taxas significativas de crescimento real. Introduzida pela Declaração de Transação Imobiliária (DTI), a nova sistemática revelouse eficiente, proporcionando um novo patamar de arrecadação do ITBI-IV, incrementando sua taxa de crescimento. De forma categórica, essa ação demonstrou o potencial que as inovações tecnológicas podem trazer de benefícios à administração tributária. A informatização permitiu maior controle da base declarada, reduzindo a prática da simulação de valor de transação. A arrecadação do ITBI-IV no período de 2000 a 2010 aumentou nominalmente $64,9 \%$ acima do PIB nominal do Município de São Paulo, valor idêntico ao alcançado pelo ISSQN, entretanto, o crescimento foi mais acelerado a partir de 2005. No período e 2005 Cadernos Gestão Pública e Cidadania, São Paulo, v. 18, n. 63, Jul./Dez. 2013 
a 2010, a arrecadação nominal do ITBI-IV cresceu $267 \%$, a venda, em valores nominais, de imóveis novos no município aumentou $133,4 \%$ e o PIB nominal $77,7 \%$. Assim é possível constatar que o mercado imobiliário apresentou um crescimento acima do PIB, o que impulsionou a arrecadação do ITBI-IV. Mas somente o mercado imobiliário aquecido não explica a expansão do tributo, pois a elevação da arrecadação foi praticamente o dobro do crescimento imobiliário, validando a hipótese da influência da ação governamental.

Para melhor compreensão do fenômeno, seria necessário buscar outros modelos estatísticos, tais como aqueles relacionados à análise de séries temporais envolvendo intervenções como as tratadas neste estudo.

Uma pesquisa interessante pode ser direcionada ao estudo de séries históricas envolvendo a análise de intervenções em séries temporais. Uma intervenção pode afetar uma série temporal de interesse de várias maneiras. Na sua manifestação, ela pode ser abrupta ou residual e, na sua duração, permanente ou temporária (Morettin e Toloi, 2004).

Outra abordagem está relacionada a formas funcionais logarítmicas em modelos de defasagens distribuídas (Wooldridge, 2006). Essa abordagem usa o logaritmo das diferenças e associa a chamada elasticidade de curto prazo, ou seja, o quanto a variação percentual em certa variável afeta a variação percentual em outra variável (variação do PIB implica variação da receita com certa elasticidade, por exemplo).

Os modelos que podem avaliar o impacto de ações governamentais transcendem a questão da arrecadação tributária quando são usados como ferramentas para identificar ações que acarretem benefícios sociais, como fomentar - desenvolvimento de determinadas regiões, o que implica a criação de novas oportunidades de negócios, emprego, educação etc. Essas ações possibilitam, de forma indireta, mudanças na arrecadação sem a criação de novas hipóteses de incidência ou aumento de alíquotas.

\section{Referências}

ABRUCIO, Fernando Luiz; COUTO, Cláudio Gonçalves. "A redefinição do papel do Estado no âmbito local.' São Paulo em Perspectiva, v. 10, n. 3, jul./set. 1996, pp. 40-47.

BRASIL. Constituição da República Federativa doBrasil de 1937. Brasília:Diário Oficial da União, 10 nov. 1937. Disponível em: <www.planalto.gov.br/ccivil_03/ constituicao/constitui\%C3\%A7ao37.htm>. Acesso em 16 dez. 2013.

\section{Constituição da República} Federativa do Brasil de 1988. Brasília: Diário Oficial da União, 5 out. 1988. Disponível em: <www.planalto.gov.br/ ccivil_03/Constituicao/Constituiçao.htm>. Acesso em 16 dez. 2013.

Decreto-Lei n. 406, de 31 de dezembro de 1968. Estabelece normas aplicáveis aos impostos sobre operações relativas à circulação de mercadorias e sobre serviços de qualquer natureza, e dá outras providências. Brasília, Diário Oficial da União, de 31 dez. de 1968. Disponível em: <www.planalto.gov.br/ccivil_03/decretolei/Del0406.htm>. Acesso em 16 dez. 2013.

\section{Lei $n .5172$, de 25 de outubro de}

1966. Dispõe sobre o Sistema Tributário 
Nacional e institui normas gerais de direito tributário aplicáveis à União, Estados e Municípios. Brasília, Diário Oficial da União, de 25 out. de 1966. Disponível em: <www.planalto. gov.br/ccivil_03/leis/L5172.htm>. Acesso em 16 dez. 2013.

Ministério do Planejamento. Tesouro Nacional: Estados e Municípios. Disponível em: <www.tesouro.fazenda.gov.br/estados_ municipios/index.asp>. Acesso em: 13 abr. 2012.

BUSSAB, W. O.; MORETTIN, P. A. Estatística básica. São Paulo: Saraiva, 2003.

FAORO, Raymundo. Os donos do poder: formação do patronato político brasileiro. São Paulo: Globo, 2001.

GUJARATI, D. N. Econometria básica. São Paulo: Makron Books, 2000.

LEVINE, D. M.; BERENSON, M. L.; STEPHAN, D. Estatística Teoria e Aplicações Usando - Microsoft Excel em Português. Rio de Janeiro: LTC, 2000.

MORETTIN, P. A., TOLOI, C. M. C. Análise de séries temporais. São Paulo: Edgard Blücher, 2004.

SÃO PAULO. Prefeitura de São Paulo. Decreto 46.598, de 4 de novembro de 2005, Regulamenta o disposto nos artigos 9o-A e 9o-B da Lei n. 13.701. Publicado na Secretaria do Governo Municipal, em 4 de novembro de 2005. Disponível em: <www3.prefeitura.sp.gov. br/cadlem/secretarias/negocios_juridicos/ cadlem/integra. asp? alt $=05112005 \mathrm{D} \% 20$ 465980000>. Acesso em 16 fev. 2012.

$$
\text { Prefeitura de São Paulo. Lei 13.701, de }
$$

24 de dezembro de 2003. Altera a legislação do Imposto sobre Serviços de Qualquer Natureza - ISS. Publicado na Secretaria do Governo Municipal, em 24 de dezembro de 2003.

Prefeitura de São Paulo. Lei 14.042, de 30 de agosto de 2005. Altera a legislação do Imposto sobre Serviços de Qualquer Natureza - ISS. Publicado na Secretaria do Governo Municipal, em 30 de agosto de 2005.

SECOVI-SP. Balanço do Mercado Imobiliário 2011. Publicado na página da SecoviSP (Sindicato das Empresas de Compra, Venda, Locação e Administração de Imóveis Residenciais e Comerciais de São Paulo). Disponível em <http://balanco.secovi.com. br/2011/download/balanco2011.pdf>. Acesso em 21 set. 2013.

WOOLDRIDGE, J. M. Introdução à econometria: uma abordagem moderna. São Paulo: Pioneira Thomson Learning, 2006.

\section{Notas}

1. Consideram-se tributos próprios dos municípios aqueles de sua competência exclusiva, ou seja, excluem-se as transferências correntes.

2. O sistema tributário nacional prevê que $50 \%$ da arrecadação do IPVA deve ser repassada aos municípios de registro dos automóveis e $25 \%$ do ICMS arrecadado nos estabelecimentos situados no município.

3. A denominação Sisa (ou Siza na grafia da época do Brasil Império) possui duas interpretações: uma sigla (Serviços de Impostos de Sua Alteza) e siza, proveniente da palavra latina excidere, que significa cisalhar, fatiar, partilhar.

4. Com base no Código Civil, os bens transmitidos aos herdeiros seguem uma proporção previamente definida na partilha, cabendo a cada sucessor o seu quinhão.

5. A alíquota mínima permitida é de $2 \%$, entretanto 
algumas cidades fazem abatimentos da base de cálculo que tornam a alíquota efetiva abaixo da mínima.

6. Toda a legislação referente aos tributos do Município de São Paulo pode ser encontrada na página da Secretaria Municipal de finanças: <www.prefeitura.sp.gov.br/cidade/secretarias/ financas/legislacao>.

7. Caracteriza-se empresa de economia mista quando mais da metade das ações com direito a voto pertence ao Estado.

8. Grupos de serviços se referem a atividades que apresentam uma característica comum. Podese citar como exemplo o grupo bancos, o qual envolve aqueles serviços vinculados à atividade bancária de forma direta.

9. Códigos de serviços são subdivisões dos grupos de serviço que apresentam atividades com maior similaridade. Podem ser consultados no link <http://ww2.prefeitura.sp.gov.br/arquivos/ secretarias/financas/legislacao/IN-SF-Surem04-2010-Anexo-1.pdf>.

10. Tomador de serviços entende-se como aquele que retém o valor devido de ISS na fonte, ou seja, deve cumprir a determinação legal de reter o montante do ISS devido pelo prestador (fonte). Pode-se consultá-lo no link <http:// ww2.prefeitura.sp.gov.br/arquivos/secretarias/ financas/legislacao/IN-SF-Surem-04-2010Anexo-2.pdf>.

11. Prestadores de serviços entendem-se como aqueles que realizam o serviço e recolhem diretamente o valor devido do ISS (próprio).

12. A significância estatística baseia-se no cálculo de probabilidades e, normalmente, utiliza um nível de significância de 5\%. Para mais detalhes, ver Bussab e Morettin, 2003.

13. O ISSQN tem pico de arrecadação em janeiro de cada ano, reflexo dos serviços prestados em dezembro e o recolhimento em janeiro; o ITBI-IV apresenta o ponto mais elevado em dezembro, momento em que os investidores imobiliários desejam encerrar o ano fiscal e pequenos proprietários buscam utilizar recursos do 130 salário para comprar ou regularizar seu imóvel (lavrar a escritura, fato gerador do ITBIIV). Quanto ao IPTU, o pico ocorre no mês de fevereiro, momento em que ocorrem as notificações de lançamento, das quais $25 \%$ são pagas à vista com desconto, ou seja, quase um quarto de toda a arrecadação do IPTU ocorre nesse mês.

14. A nomenclatura parâmetro é utilizada na estatística para definir uma medida da população a qual quer se prever por meio da estimação paramétrica (obtida da amostra), que pode ser pontual ou intervalar.

15. Geralmente, no teste de hipóteses, ser igual a zero refere-se à hipótese nula.

16. Tipo ou grupo de tomadores foi definido como aqueles que devem observar a Lei $n$. 14.042/05 e os que não foram abrangidos pela mesma lei.

17. O recurso utilizado do Excel (versão 2007) pode ser implantado pelo suplemento "Ferramenta de análises". Após a instalação desse suplemento, é preciso buscar a opção "Dados", em seguida "Análise de dados", "Regressão", para aplicar os testes estatísticos necessários para o problema (LEVINE; BERENSON; STEPHAN, 2000).

18. Do inglês p-value. Refere-se ao nível descritivo, normalmente adotado como $5 \%$, ou seja, p-valor crítico de 0,05. Nesse caso, valores abaixo do valor crítico 0,05 rejeitam a hipótese nula (apresentam significância estatística).

19. O valor atribuído é obtido a partir de informações de transações e ofertas de imóveis de características similares quanto à região, idade, área construída, área de terreno e a outras informações relevantes que possam influenciar o valor da transação. 